\title{
EL JAGUAR EN FLOR: REPRESENTACIONES DE PLANTAS EN LA ICONOGRAFÍA AGUADA DEL NOROESTE ARGENTINO'
} JAGUAR IN BLOOM: REPRESENTATIONS OF PLANTS IN AGUADA
ICONOGRAPHY OF NORTHWESTERN ARGENTINA

\section{María Bernarda Marconetto*}

En el presente trabajo, a partir del caso de análisis de la "no-representación" de vegetales en la iconografía Aguada del Noroeste Argentino, exploramos algunas ideas que nos permitan evitar la trampa interpretativa naturalista que invita a buscar en registros materiales no occidentales categorías generadas por la modernidad. Nos proponemos repensar y reflexionar acerca de algunas representaciones apelando al rol de lo ambiguo y la multirreferencialidad, y discutir algunas interpretaciones acerca de algunos de los elementos relevantes de la imaginería Aguada.

Palabras clave: Plantas, representación, Anadenanthera, jaguar, Aguada, Noroeste Argentino

By the analysis of the "non-representation" of flora in the Aguada iconography from Northwestern Argentina, we explore ideas that invite us to reject naturalistic interpretations. Such interpretations imply an application of categories generated by modernity on non-Western material records. We propose to re-think representations by taking account ambiguity and multi-referentiality, as weel as to discuss interpretations of some relevant elements of the Aguada imagery.

Key words: Plants, representation, Anadenanthera, jaguar, Aguada, Northwestern Argentina

\section{INTRODUCCIÓN}

Las ideas que aquí presentamos nacen inicialmente de algunas reflexiones ligadas a la práctica de la arqueobotánica que llevaron luego a revisar la idea de "no-representación" de vegetales en la iconografía Aguada del Noroeste Argentino. Hace algún tiempo nos preocupan los inconvenientes que puede generar el uso acrítico de la clasificación linneana en arqueobotánica (Marconetto 2008), en tanto el registro con el que trabajamos es resultado de prácticas de grupos cuya ontología lejos está del naturalismo (sensu Descola 2012) que generó la clasificación occidental del mundo. Este punto tal vez podría hacerse extensivo a una escala más amplia y reflexionar acerca de la posible arbitrariedad metodológica que cometemos los arqueólogos al hacer recortes tales como arqueobotánica, zooarqueología y otros, en general asociados al vínculo de los humanos con diversos elementos de "la naturaleza". Si bien en general los resultados de estos estudios se cruzan en algunas síntesis finales e intentamos integrar información surgida de los subequipos a los que pertenecemos, puede resultar difícil volver a unir lo arbitrariamente fragmentado. Recortamos al abordarlo un registro que, algunas discusiones que se vienen dando en antropología, nos señalan como no recortable. En particular referimos a las investigaciones pioneras de Strathern (1980), a

* María Bernarda Marconetto, Instituto de Antropología de Córdoba (CONICET) Universidad Nacional de Córdoba, email: bermarconetto@yahoo. com.ar 
Descola (2012) desde un campo como la antropología de la naturaleza, o Viveiros de Castro $(2004,2012)$ desde su propuesta del perspectivismo amerindio, la obra de Kopenawa y Albert (2010), y diversos -demasiados para ser pasados por alto- trabajos etnográficos, que muestran claramente la arbitrariedad de la fragmentación en estas parcialidades naturales. Tal vez la arqueología debiera temer menos a posibles erróneas analogías etnográficas que a las ciertamente erróneas analogías a nuestro cartesiano modo de ver el mundo.

En un intento de sortear este problema, nos propusimos una suerte de ejercicio que nos estimulara a reflexionar. Tomar las plantas -ítem del registro arqueológico con el que trabajamos desde hace años en el campo de la arqueobotánica- y, como invita Latour (1991), seguir las madejas a donde quiera que nos lleven. Este intento requería empezar por alguna hebra, y la iconografía, alejada en principio de la arqueobotánica, ofrecía un interesante potencial. En particular, porque nuestras investigaciones se vinculan a contextos que la arqueología argentina define como pertenecientes a la Cultura Aguada (ver González 1964, 1977, 1998; Pérez Gollán 1986, 1991; Kusch 1991; Callegari 2001; Laguens 2004, 2006; Gordillo 2009; entre otros), cuya rica iconografía está poblada de felinos y diversidad de figuras de humanos y no humanos, a veces reconocibles, a veces transformándose. Y, sin embargo, en relación con lo que nos convoca, las plantas, suele afirmarse que en Aguada no hay representaciones vegetales, "solo una única representación” señala González (1998: 199, figura 143) (fig. 1). Luego, una publicación de Fernández Chiti (1998) señala algunos diseños Aguada como representativos de algunas plantas psicoactivas, los frutos de Datura stramonium, "chamico", y ciertas formas que asigna al llamado "cactus de los cuatro vientos" o "San Pedro", Trichocereus pachanoi.

Ante este aparente escaso registro, decidimos hacer una experiencia, tomar "ojos prestados". A una estudiante de los primeros años de la carrera de Antropología de

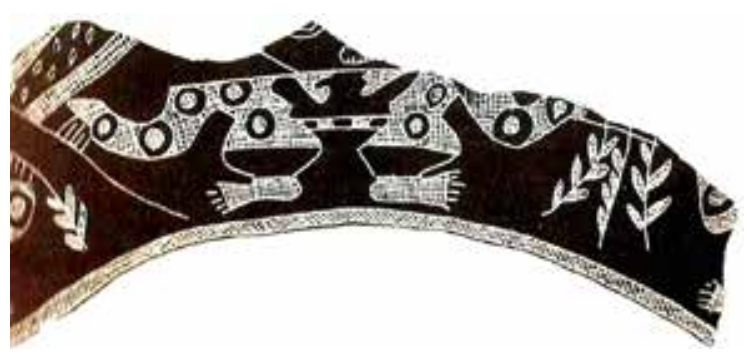

Figura 1. "Único caso en que se reconocen representaciones de vegetales en un vaso Aguada" (González 1998: 199 [figura 143]). Figure 1. "Only known case of recognized representations of flora in an Aguada vase" (González 1998: 199 [Figure 143]). la Universidad Nacional de Córdoba, virgen de relatos Aguada, vacía de jaguares y sacrificadores se le dio una consigna simple: buscar plantas en la iconografía, mira y ve qué te remite a plantas. Y así comenzó a observar publicaciones de diversos autores en los que aparecieran diseños definidos como Aguada (Bedano et al., 1993 [1974]; González 1977, 1998; Goretti 2006, 2007; Gordillo 2009). Y lo que vimos, cuando miramos -con ojos ajenos en especial-, es que las plantas parecían comenzar a aparecer. La estudiante comentó un día "aquí me parece hay una plantación", aunque el epígrafe refería a un guerrero con armas (fig. 2). Ciertamente fue convincente para quienes estábamos allí, gente leída en guerreros y jaguares. Sin embargo, no se trata aquí de hablar de pareceres, sino de seguir las hebras de una madeja e intentar al menos comprender el entramado del que participa el registro con el que trabajamos. ¿Habría espacio para las plantas, asociadas en general -por nosotros- al mundo femenino en un mundo masculino de jaguares, sacerdotes y guerreros? Es posible. ¿Realmente están ausentes las plantas o enfrentamos dificultades metodológicas para verlas? ¿Qué rol juegan la ambigüedad y las representaciones no 'naturalistas' de las imágenes?

\section{Plantas ambiguas en un mundo multirreferencial}

Antes de comenzar a abordar el tema de la ambigüedad, creemos necesario señalar que los registros arqueológicos definidos como Aguada en la arqueología del Noroeste Argentino han sido históricamente asociados a la dinámica cultural de los Andes (ver reseñas de la historia de las investigaciones en Gordillo 2009, Gastaldi 2010). Sin embargo, los vínculos de las poblaciones prehispánicas de esta región de la Argentina con las llamadas tierras bajas y aun con grupos amazónicos vienen discutiéndose desde principios del siglo xx (ver reseñas de estos debates en relación con Aguada en Gastaldi 2010, Pazzarelli 2011). Asignar el registro acerca del cual reflexionaremos específicamente a uno de estos espacios, Andes o Amazonas, ámbitos que los debates aún vigentes no

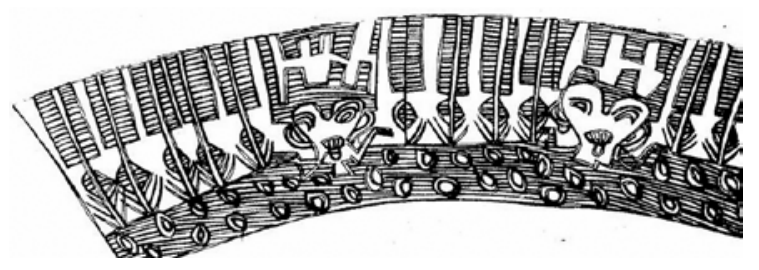

Figura 2. "Guerreros y armas" (en González 1998. Apéndice). Figure 2. "Warriors and weapons" (in González 1998. Appendix). 
logran recortar claramente, no es un objetivo viable de alcanzar aquí. No obstante, resultan interesantes como herramienta reflexiva los acercamientos analíticos entre estas dos regiones, puntualmente aquellos ligados al concepto de "multinaturalismo" en términos de Viveiros de Castro (2004), donde lo que humanos y no humanos comparten es la cultura y no la naturaleza. Este solo punto representa una fractura crucial respecto de nuestra propia concepción, un quiebre ontológico, y genera un válido instrumento para intentar repensar materialidades de grupos prehispánicos de tierras altas o bajas. Se ha propuesto que la cosmología andina comparte los mismos fundamentos de esta economía simbólica presentada originalmente para Amazonas (Cavalcanti-Schiel 2007: 10), siendo ya diversos los trabajos etnográficos llevados a cabo en los Andes en esta línea (Arnold \& Yapita 2000; Lema 2014; Pazzarelli 2014; entre otros). En cuanto a la ahistoricidad que puede entenderse presentan los casos etnográficos, es necesario aclarar que los mismos son empleados aquí simplemente como elementos de quiebre de las propias miradas.

El mundo andino está cargado de sentidos múltiples. La etnografía ha dado sobrada cuenta de esta particularidad y ha apelado a diversos conceptos para discutir esta cuestión como multirreferencialidad o intertextualidad (Arnold \& Yapita 2000). Se trata de un espacio en el que las analogías y lo ambiguo son protagonistas. En términos de Descola (2011, 2012), los Andes se adscribirían a la fórmula ontológica que este autor llama Analogismo. Fundada en el reconocimiento de una discontinuidad general de las interioridades y la fisicalidades, construyendo así un mundo poblado de singularidades, un mundo que sería difícil de habitar y de pensar en razón de esta enormidad de diferencias que lo componen, si no nos esforzáramos por encontrar entre los seres existentes, redes de correspondencia que permiten conectarlos (Descola 2011: 87).

En este contexto de singularidades y analogías donde el peligro acecha, como ilustra Cereceda (1988). Entendemos que lo ambiguo, entendido este término como pasible de ofrecer más de un significado, puede jugar un rol no menor. Algunos términos ligados a las plantas presentan sugerentes ejemplos. Mallqui designa tanto a los árboles por su asociación con los antepasados, a las semillas y también a las momias (Hastorf \& Johannessen 1991); igualmente Sharon (2004: 63) menciona una asociación antepasado-momia-semilla en el vocablo mallqui interpretándola como una unidad conceptual. Asimismo, uno de los más recurrentes nombres dado a las semillas de Anadenanthera, Willca o Vilca también refiere al sol, lo sagrado y al árbol de semillas psicoactivas en aymara.
En relación con estos puntos, nos interesa intentar plantear algunos posibles ejes de ambigüedad en relación con la cuestión de la representación de los vegetales en el caso que nos ocupa, Aguada. Un elemento que llama notablemente la atención en relación con los motivos Aguada lo señalan Llamazares y Martínez Sarasola (2006) refiriendo a híbridos y metamorfosis en estos diseños. Los mencionados autores marcan, respecto de motivos vinculados a la transformación, que "si bien los elementos que participan son claramente zoomorfos, el mecanismo de generación de las formas corresponde más a un crecimiento propio de lo vegetal" (Llamazares \& Martínez 2006: 85). Esta idea solo es una mención en un texto que aborda el arte indígena y el chamanismo, creemos la misma puede encadenarse con cuestiones que discutiremos más adelante.

\section{Las armas-plantas}

Una antigua publicación de Yacovleff y Herrera (1934) "El mundo vegetal de los antiguos peruanos", reseña diversidad de motivos y representaciones de vegetales en los Andes plasmadas en diferentes soportes: cerámica, grabados, textiles, metales. Entre esas representaciones, un personaje interesante que se presenta recurrente y atrajo nuestra mirada es el llamado por los autores "el portador de vegetales" (fig. 3). Se trata de un personaje con una gestualidad específica, parado de frente con plantas en ambas manos. Plantas en las que destacan la parte aérea y las raíces. Plantas de diversas especies. Es notable que el gesto de estos personajes también se repite en diferentes diseños de la iconografía andina en personajes portadores de cetros, de cabezas trofeos, de hachas o armas (ver ejemplos, para Aguada, González 1977, 1998; Bedano et al., 1993; para Tiahuanaco, Berenguer 2000; para Moche, Gallardo et al. 1990).

Apelando a la idea de ambigüedad, nos interesa rescatar algunas imágenes recurrentes en diseños Aguada a partir de las cuales trazar un posible eje de ambigüedad al que optamos por llamar "armas-plantas". ${ }^{2}$ En especial nos referimos a ciertos personajes cuya gestualidad en

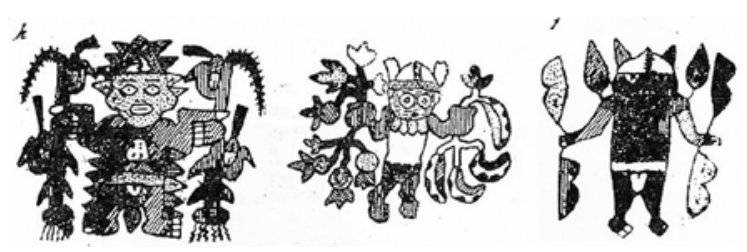

Figura 3. Caso de representación de "portador de vegetales", Nasca (en Yacovleff \& Herrera 1934).

Figure 3. A case of representation of a "vegetable bearer", Nasca (in Yacovleff \& Herrera 1934). 
Aguada remite a los portadores de vegetales que ocurren a lo largo de los Andes. Estos personajes en Aguada han sido descritos en general como guerreros portando, o flanqueados, por armas. Sin embargo, son notables algunas particularidades en la representación de estas "armas" cuya flexibilidad en algunos casos remite a lo vegetal, así como la presencia de potenciales raíces (figs. 4 y 5 )

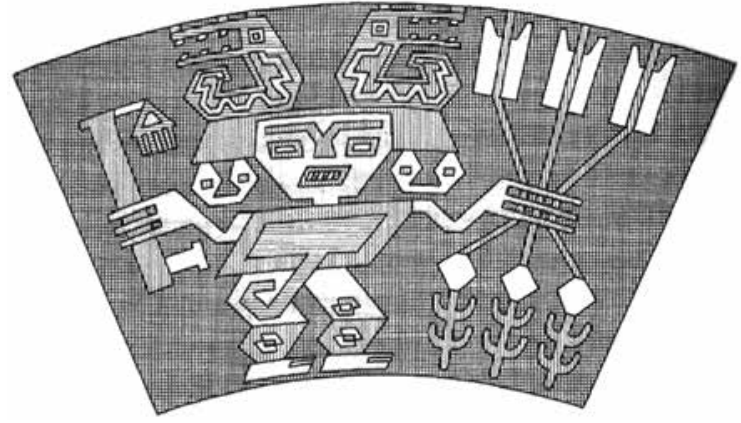

Figura 4. Destáquese la flexibilidad de los astiles y los elementos asignables a raíces (González 1998).

Figure 4. Notice the flexibility of the handles and elements that may represent roots (González 1998).

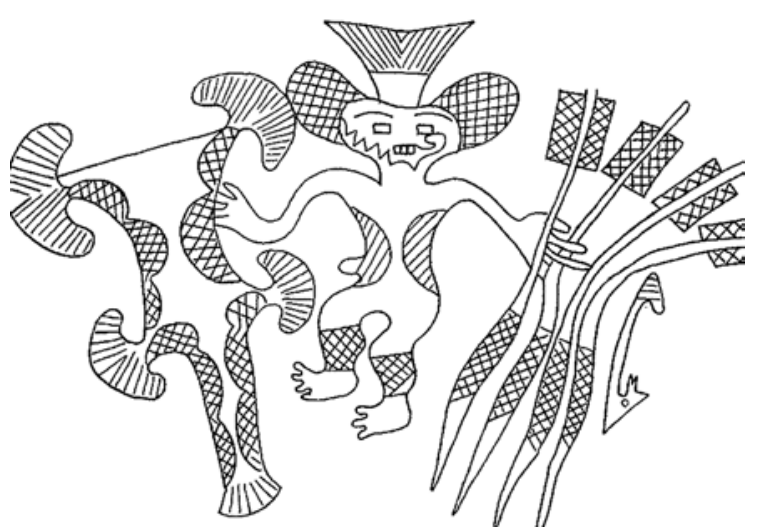

Figura 5. Destáquese la flexibilidad de los astiles (González 1998). Figure 5. Notice the flexibility of the handles (González 1998).

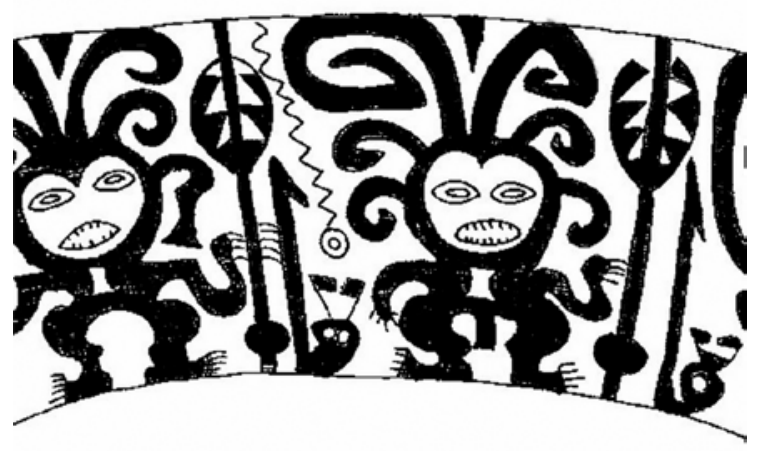

Figura 6. Guerreros flanqueados de "armas/plantas" (González 1998). Figure 6. Warriors surrounded by "weapons/plants" (González 1998). al tiempo que en diversas oportunidades la morfología resulta fácilmente asimilable a plantas (figs. 6, 7 y 8).

Podría surgir la pregunta: y si son plantas ¿qué plantas son? Y tentarnos a una identificación taxonómica. Sin embargo, en esta instancia no nos interesa demasiado el posible taxón, sino el carácter ambiguo que puedan presentar estos elementos. Esta es una cuestión que aquí solo esbozamos en algunos ejemplos gráficos a fin de argumentar acerca del potencial de análisis de lo ambiguo, de marcar una agenda en un tema que pretendemos seguir explorando. Resulta sugerente para continuar en esta línea la idea discutida entre Kounen y colaboradores (2008), acerca de la ambigüedad del mundo de los chamanes, que al igual que las plantas, pueden curar o matar.

\section{Las manchas-semillas}

El registro arqueobotánico del valle de Ambato, en la provincia de Catamarca (Argentina), evidencia el rico vínculo entre los ocupantes de la región entre los siglos VI y x y las plantas (Marconetto 2008). Uno en

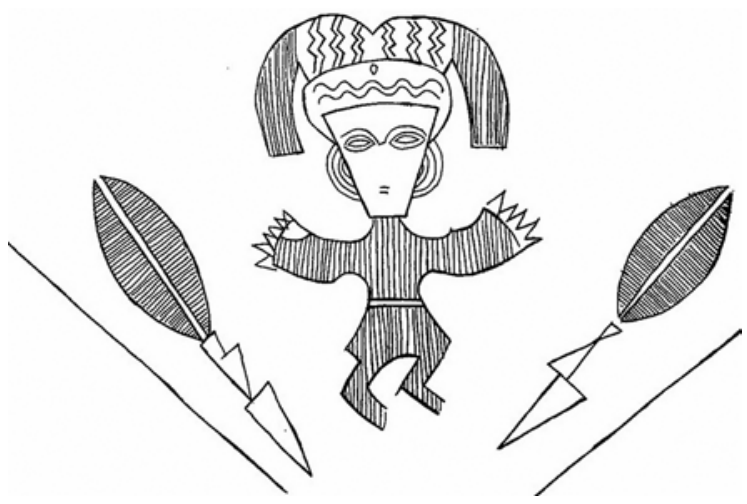

Figura 7. Guerreros flanqueados de "armas/plantas" (González 1998). Figure 7. Warriors surrounded by "weapons/plants" (González 1998).

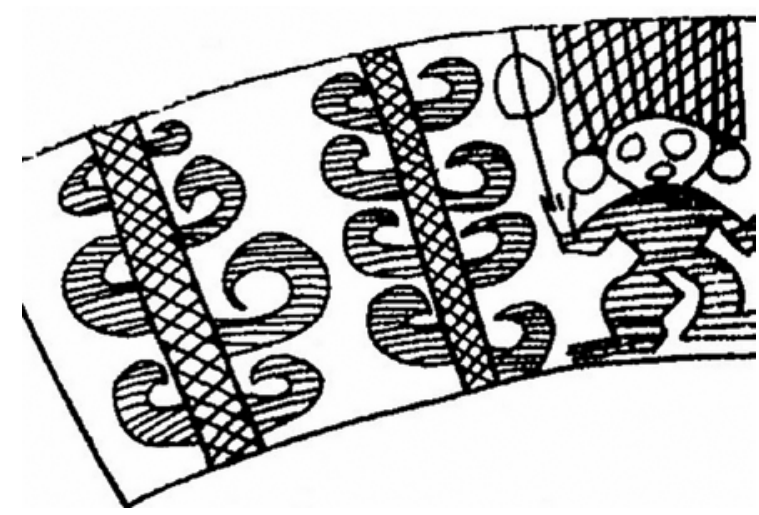

Figura 8. Guerreros flanqueados de "armas/plantas" (González 1998) Figure 8. Warriors surrounded by "weapons/plants" (González 1998). 
particular, aunque no exclusivo de Aguada, es el estrecho lazo con las leguminosas. Estas plantas con vainas y semillas han participado íntimamente en la vida de estas comunidades. Brindando techo y abrigo (Prosopis y Acacia); transformando cuerpos desde el alimento (Prosopis), transformando alimentos por medio del fuego (Prosopis, Acacia); transformando la materia -arcilla y metal- mediante otros fuegos (Prosopis) y en particular transformando, o tal vez mejor expresado ampliando percepciones, con el consumo de plantas psicoactivas (Anadenanthera).

Como mencionamos anteriormente, los diseños representando transformaciones en la iconografía Aguada son recurrentes, aunque a simple vista en estas solo parecen estar involucrados humanos y animales. Resulta cuanto menos extraña la ausencia en las representaciones de quien ha sido largamente señalada como vehículo de estas transformaciones: Anadenathera (Pérez Gollán \& Gordillo 1993).

La representación del cebil o vilca (Anadenanthera) ha sido sugerida, para el área andina, por Knobloch (2000), quien ha argumentado la interpretación de algunos elementos presentes en motivos de la cerámica Wari como diferentes partes de la planta (flores, hojas, vainas). Mulvany (1984) ha registrado la presencia de motivos fitomorfos, en particular plantas psicoactivas Brugmansia y Anadenanthera, en el Obelisco Tello de Chavín de Huantar. Por su parte, Torres (2013) ha señalado la representación de motivos posibles de ser adscritos a partes de la planta de Anadenanthera, en diseños Moche de la costa peruana. Los mencionados trabajos muestran evidencias de la representación de hojas, vainas y flores de cebil o vilca. Sin embargo, las semillas parte de la planta empleada para la ingesta por diferentes vías -fumitoria, oral, nasal o rectal- de sus principios activos (Ott 1996) parece no haber sido representada o, simplemente, no ha sido mencionada.

Las semillas de las legumbres del árbol de Anadenanthera colubrina (Vell.) Brenan, que crece en el noroeste de Argentina así como en otras regiones de América del Sur, son de forma circular a subcircular, aplanadas, de color marrón obscuro, de aproximadamente un centímetro de diámetro, su endocarpio presenta la particularidad de mostrar una suerte de diseño circular interno presentando la semilla una forma semejante a un círculo concéntrico (fig. 9).

El diseño de círculos concéntricos es ciertamente recurrente en la iconografía prehispánica, sin embargo nos interesa puntualmente el caso de Aguada. Hemos examinado en motivos plasmados en la cerámica los elementos circulares, asociados en la literatura a "manchas de jaguar", cuya forma, desde nuestra perspectiva,

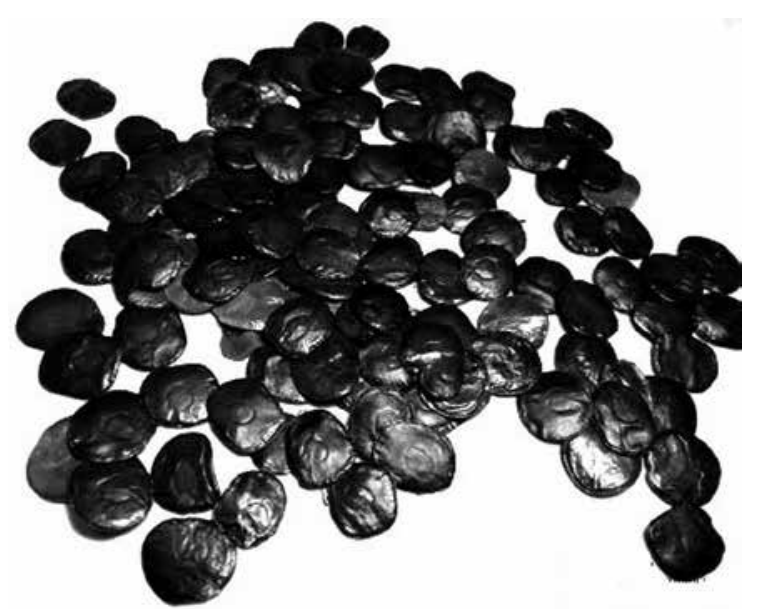

Figura 9. Semillas de Anadenanthera colubrina. Figure 9. Seeds of Anadenanthera colubrina.

podría asociarse al vehículo más que al resultado de la transformación de los personajes representados.

Antes de abordar este punto, entendemos que es pertinente revisar de dónde procede la idea de asociar estos elementos circulares a manchas de jaguar. Gastaldi (2010) presenta una interesante discusión acerca del surgimiento de "lo draconiano" -modo en que se nombró inicialmente al conjunto de representaciones que luego fueron asignadas a la Cultura de La Aguada- y su inserción en la historia no solo de la arqueología sino de Argentina. De estas discusiones participan a principios del siglo xx las miradas de pioneros de la arqueología del Noroeste Argentino como Boman, Ambrosetti, Lafone, Debenedetti, Quiroga, Casanova. Fue Levillier quien en 1927 propuso que las figuras definidas como draconianas se trataban en realidad de figuras felinizadas. El interés de Levillier era plantear la existencia de cierta unidad mitológica entre las culturas indígenas, no solamente andinas, sino compartida por varios pueblos de las tierras bajas y en el marco de esa concepción mencionaba que "no era concebible que los diaguitas escaparan a la unidad tan claramente patentizada en las naciones vecinas del norte, ni era aceptable que donde las demás representaban al dios felino, particularmente al jaguar, ellos imaginaran un dragón (Levillier 1927, en Gastaldi 2010).

Al comparar Levillier la cerámica Recuay -que Tello en Perú asociaba a la representación de un dios felino- con la alfarería draconiana, encuentra similitudes ciertamente notables. Es factible preguntarnos ¿de dónde toma Tello, y por ende Levillier, la relevancia del jaguar? La respuesta es: de "lo etnográfico". Estas ideas se basaron en la percepción de quienes recopilaban información etnográfica a fines del siglo xIX y principios 


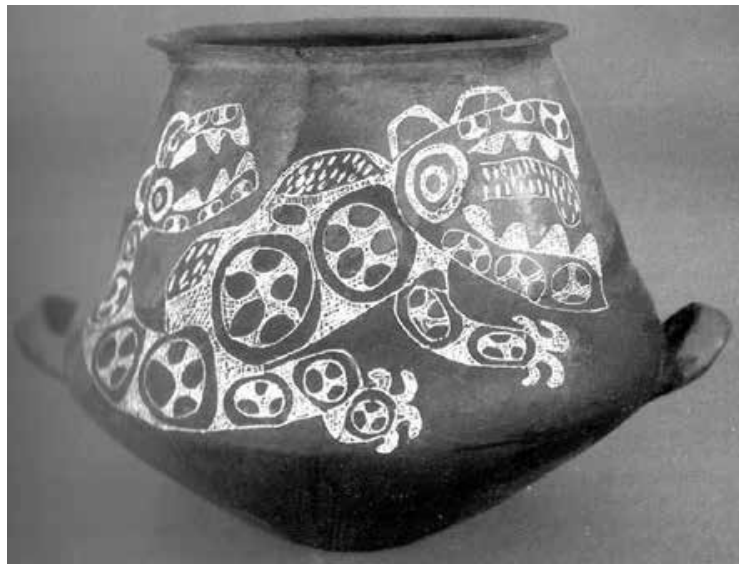

Figura 10. Representación de felino con manchas múltiples (González 1998).

Figure 10. Representation of a feline with spots (González 1998).

del xx, fundada en que existía un "miedo" ancestral a una "naturaleza" indómita representada por el jaguar.

En rigor de verdad, nada tiene de extraño que siendo el tigre la fiera más difundida y cruel del continente, actuara en forma de obsesión sobre la sensibilidad primitiva aterrorizada, hasta el punto de establecerse en las divinidades y ocupar un lugar esencial en las imágenes de las obras de arte. El indio de la región serrana del callejón de los Mochicas y de la región Diaguita veneraron a lo que adoraban, por bueno; y lo que temían por malo. A ambas fuerzas respetaron y sirvieron, y a ambas dirigieron sus holocaustos interesados. La esperanza como el espanto, dilatan los ojos y mueven la fantasía al desequilibrar el juicio. De allí las fábulas, las creencias y supersticiones transmitidas de padres a hijos, transportadas después a la cerámica y a los enseres de uso diario (Levillier 1927: 74, en Gastaldi 2010, lo destacado es nuestro).

Definitivamente, estas ideas merecerán repensarse desde etnografías más sensibles a las que tenemos acceso hoy, un siglo más tarde, en donde el chamanismo es entendido como mundo ambiguo; donde el concepto de naturaleza es claramente asumido como una construcción de la modernidad; etnografías que entienden que los mal llamados alucinógenos no "alteran el juicio" sino que amplían la consciencia; y que tornan serio el pensamiento indígena en lugar de rotularlo como "fábulas, creencias y supersticiones".

Esta invitación a repensar algunas ideas no resta importancia al jaguar, figura a la que tanto la etnografía como la arqueología contemporáneas continúan presentando como un elemento relevante. De hecho, los motivos recuperados en contextos arqueológicos parecen mostrarnos que cuando en Aguada quisieron presentar un jaguar lo hicieron. Podemos verlos representados con sus manchas múltiples -como son las manchas del jaguar-, siendo por cierto este personaje un elemento que se repite (fig. 10).

Sin embargo, muchas otras veces se representan seres que nos resultan familiares o no, humanos, animales o transformaciones. Y en esas ocasiones, las "manchas" -o mejor dicho estos círculos- remiten plausiblemente al vehículo de la transformación: las semillas de cebil. Las figuras nos presentan a humanos y no humanos, incluyendo jaguares, portando estos círculos (figs. $11 \mathrm{y}$ 12). Pensamos es válido preguntarse si es posible que el jaguar en ocasiones portara la impronta del cebil y llevara esta marca al igual que humanos, serpientes, monos, sapos, aves, camélidos, etc.

Tal vez desde esta óptica el jaguar, aun sin perder importancia, saldría del centro. Porque son las plantas las que permiten el diálogo y el entendimiento entre las especies -incluido el jaguar- como lo han señalado desde Castaneda en los sesenta, hasta Kopenawa y Albert (2010), así como diversidad de etnografías (ver Narby \& Huxley 2009). Y, en Aguada, el cebil posiblemente estableció ese diálogo.

Nuevamente no es aquí lo relevante, igual que en el caso de las armas-plantas, establecer y definir si son manchas o si son semillas. Tal vez no importa. Lo que importa es que nuevamente resulta ambiguo. Siguiendo en esta línea, existe en relación precisamente a la idea de entendimiento, otro eje ambiguo, que podríamos llamar semilla [planta]-manchas-sentidos.
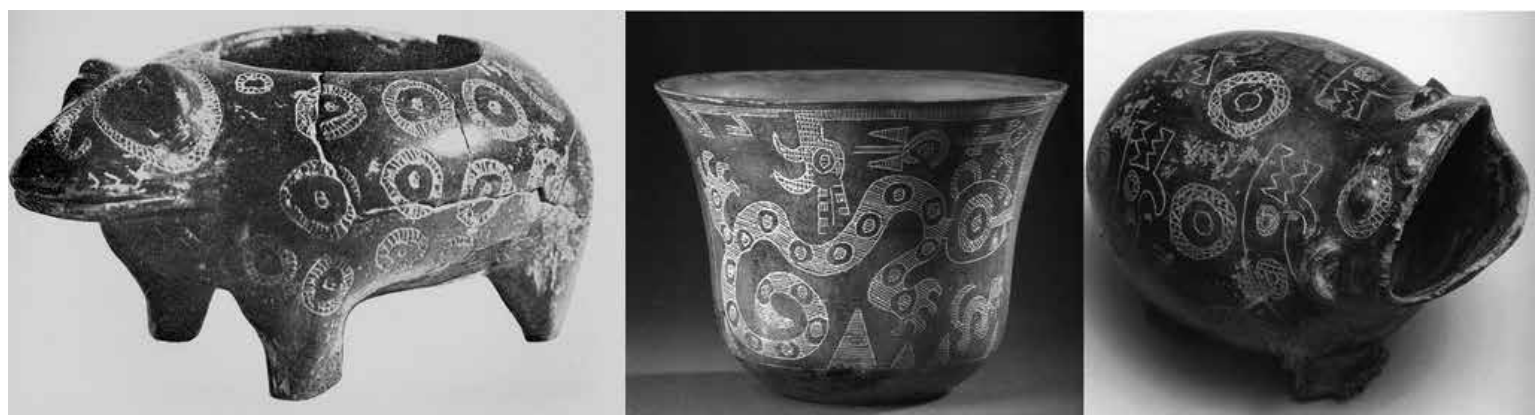

Figura 11. Círculos concéntricos en diversos especímenes (Goretti 2006).

Figure 11. Concentric circles in several specimens (Goretti 2006). 


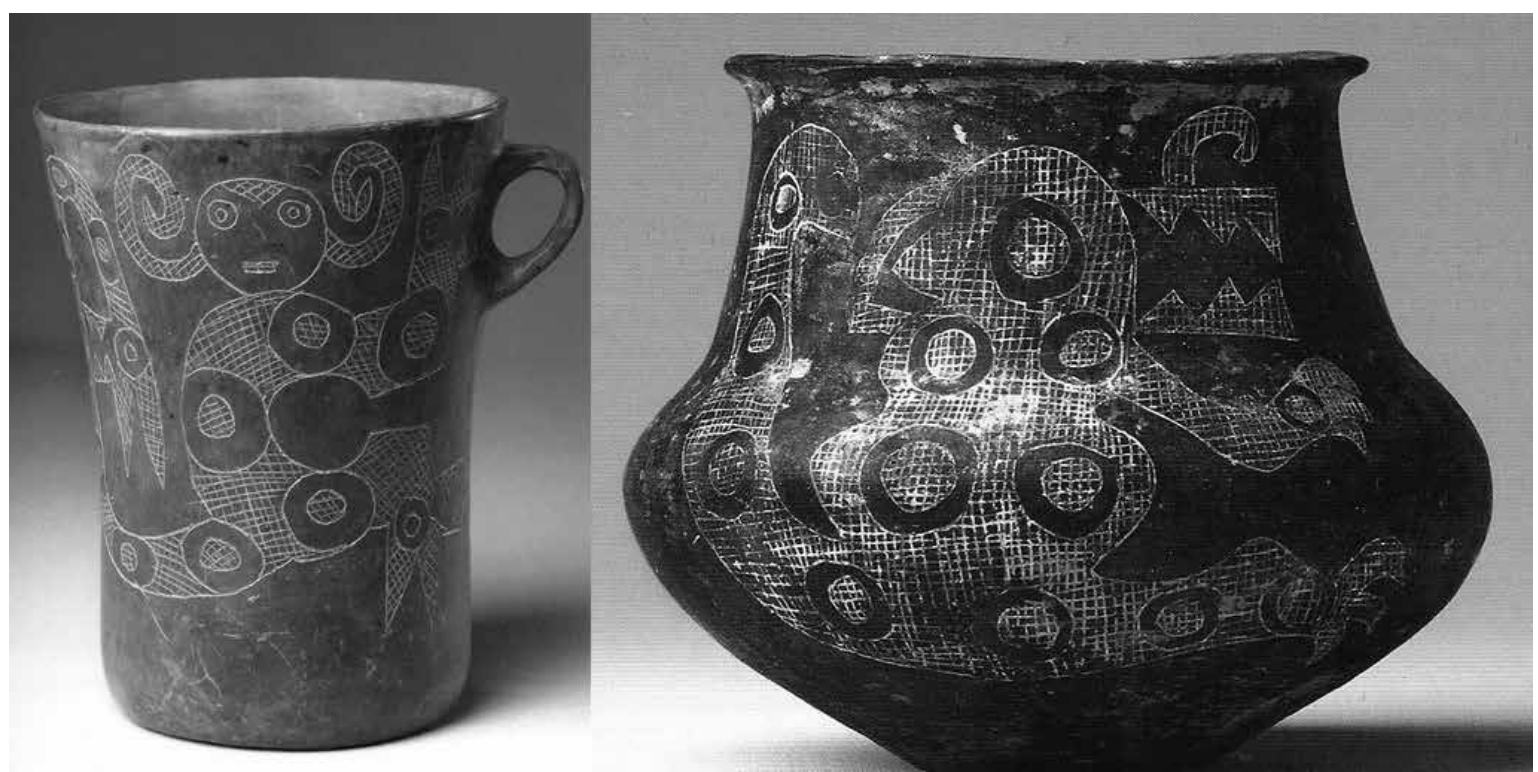

Figura 12. Círculos concéntricos en diversos especímenes (González 1977; Goretti 2006).

Figure 12. Concentric circles in several specimens (González 1977; Goretti 2006).

Resulta notable en múltiples representaciones cómo estas manchas/semillas, e incluso partes de plantas -como hojas de leguminosas- se replican en el lugar de los órganos sensoriales: ojos, boca y en ocasiones oídos (figs. 13 y 14). Desde nuestra perspectiva, entendemos que esto no es aleatorio y ameritará continuar indagando en esta dirección. En relación con este punto, resuenan los estudios referidos a fenómenos de sinestesia (Howes 2006), situación que implica la asimilación conjunta de sensaciones de diferentes sentidos en un mismo acto perceptivo (p. e., oír colores, ver sonidos, sensaciones gustativas al tacto). Este fenómeno ha sido reportado por personas bajo la influencia del consumo de plantas psicoactivas y puede ser en sí mismo entendido como multirreferencialidad sensorial. El hecho de que estos círculos/semillas ocupen el lugar de los ojos específicamente, creemos es una cuestión no menor en términos de la relevancia que se ha dado a su representación en imágenes vinculadas a estados alterados de consciencia (Lewis Williams \& Pearce 2009). Siguiendo en esta línea es necesario mencionar a Viveiros de Castro (2012) quien destaca

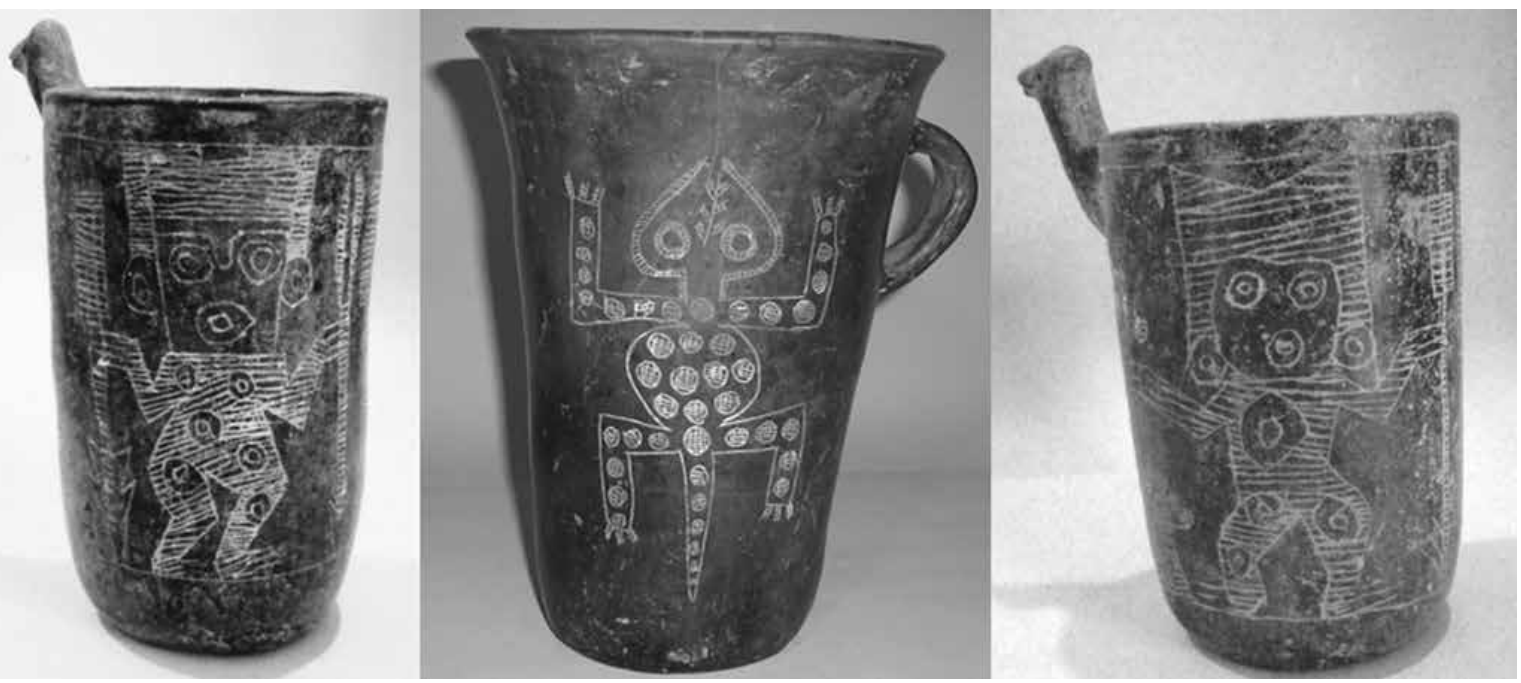

Figura 13. Círculos concéntricos replicados en órganos sensoriales (fotos de archivo personal Sofía Juez).

Figure 13. Concentric circles found repeatedly in sensory organs (Sofia Juez's personal archives). 

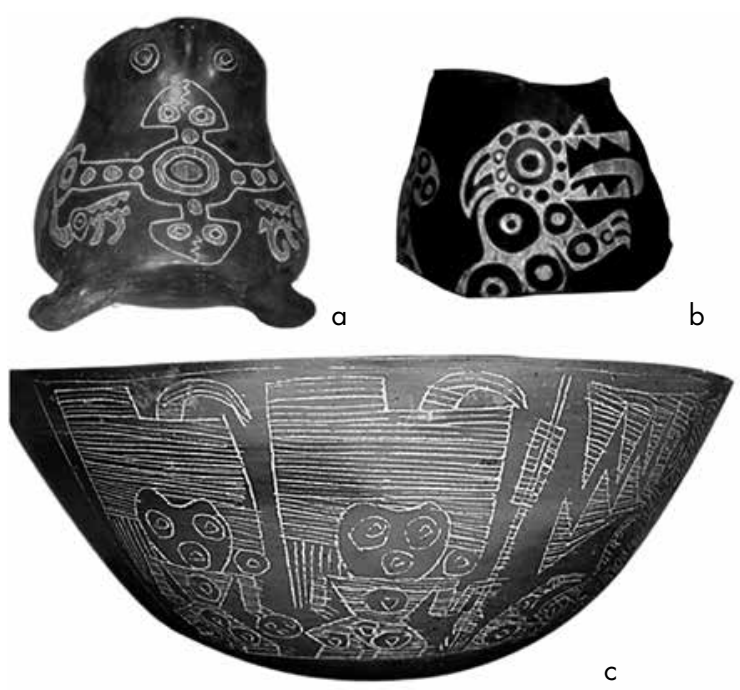

Figura 14. a) (Gordillo 2009); b) archivo personal Sofía Juez; c) círculos concéntricos replicados en órganos sensoriales. Figure 14. a) (Gordillo 2009); b) Sofía Juez's personal archives; c) concentric circles found repeatedly in sensory organs.

que el énfasis en los ojos y la mirada está claramente expresado en diversas etnografías. Reseñando diversos casos, este autor señala la importancia de la visión en las cosmologías amerindias y justifica el haber empleado el término perspectiva como elemento sustancial del pensamiento amerindio. Sin embargo, destaca que si bien las diferencias se pueden expresar en términos visuales, no lo son meramente, son relacionales "usted no ve una diferencia, la diferencia es lo que lo hace ver".

\section{Algunas reflexiones sobre la ausencia}

Los vegetales ocupan en la escala de los seres vivos del planeta prácticamente el último lugar para los occidentales. Son entendidos como seres pasivos, y aunque es alta su relevancia como recursos, no son considerados más allá de esa frontera. Esto se refleja también en la práctica arqueológica. Los estudios arqueobotánicos son recientes con relación a otro tipo de análisis, y en este ámbito también se reducen, en la mayoría de los casos, a un abordaje ligado a su uso como recurso. Los análisis iconográficos, exceptuando algunos trabajos, tampoco han prestado demasiada atención a su representación en relación con otros elementos. En este escenario, a fin de no caer en la trampa interpretativa naturalista que convierte a no humanos en recursos, nos resultó interesante indagar el lugar de las plantas en ámbitos no occidentales, así como explorar el lugar de lo ambiguo para abordar desde la arqueología el vínculo humano-planta.
Retomando el problema presentado al inicio acerca de los recortes en registros generados por mundos no-recortables $-\mathrm{O}$ al menos no recortables a nuestro modo- inquieta cómo las categorías generadas por la modernidad no funcionan. Algunas de las ideas traídas aquí invitan a deconstruir incluso nuestra más amplia categorización de los no humanos: los "reinos" mismos. La construcción moderna de ciertas categorías como "animal", "vegetal" o "humano" en tanto esferas disociadas, nos lleva a buscar en el registro arqueológico: animales y/o plantas, y/o humanos, y así perdernos de interrelaciones surgidas de una comprensión del mundo que asumimos debió ser diferente a la propia.

Los contextos arqueológicos en que se ha recuperado el material con las representaciones a las que hemos aludido aquí, podrían asociarse a ámbitos que involucran prácticas chamánicas (Pérez Gollán \& Gordillo 1993; Laguens \& Gastaldi 2008; Nastri 2008). Y las plantas en ese mundo están muy lejos de ocupar un espacio marginal, en particular las plantas psicoactivas.

Resulta sugerente apelar a una idea vertida en el libro de Kounen y colaboradores (2008). En su diálogo acerca de plantas y chamanes en Amazonía peruana los autores se preguntan ¿de qué hablamos al hablar de enteógenos? Y la respuesta es simple y compleja a la vez. Estas plantas ocupan un lugar central en el conocimiento del mundo, conocimiento que contradice el paradigma occidental. ¿Por qué el mundo se ordena de tal modo? -Porque la planta lo dijo, es la respuesta. Son la base de la deconstrucción misma del binomio naturaleza-cultura. Es otra epistemología. Y se preguntan, y nos preguntamos, si es posible un acto de cortesía epistemológica en el que, al menos por un momento, imaginar que creemos que lo que los chamanes dicen es cierto.

\section{NOTAS}

${ }^{1}$ Diferentes versiones de este trabajo han sido presentadas en tres reuniones, una poblada de arqueólogos, una de antropólogos y una tercera en el Museo de Plantas mágicas del Cusco en el que participaron además artistas y chamanes. El intercambio en esos espacios fue sumamente enriquecedor, y algunas ideas vertidas aquí han surgido de esos encuentros. Los comentarios de algunos colegas así como el de los revisores del trabajo, han sido un gran aporte, mi agradecimiento a ellos y a Victoria Reusa por "prestar sus ojos", sin embargo los errores aquí vertidos son responsabilidad de la autora.

2 "Flor del Arco" llaman a las flechas los Mbya Guaraní, nos cuenta Clastres (1978: 85). Dato curioso.

\section{REFERENCIAS}

ARnOlD, D. \& J. YAPITA, 2000. El rincón de las cabezas. Luchas textuales, educación y tierras en los Andes. La Paz: Editores UMSA e ILCA. 
Bedano, M. C; S. Juez \& D. RocA, 1993 [1974]. Análisis del material arqueológico de la Colección Rosso procedente del departamento de Ambato, provincia de Catamarca. Publicaciones 7. Tesis y Monografías 1. Tucumán: Universidad Nacional de Tucumán.

Berenguer, J., 2000. Tiahuanaco. Señores del lago sagrado. Santiago: Museo Chileno de Arte Precolombino.

Callegari, A., 2001. Los grabados del Rincón del Toro y el paisaje. Su relación con el sistema iconográfico Aguada. Boletín del Museo Chileno de Arte Precolombino 8: 21-33.

CavalCANTi-Schiel, R., 2007. Las muchas naturalezas en los Andes. Periferria: Revista de recerca i formació en antropología 7: 1-11.

Cereceda, V., 1988. Aproximaciones a una estética andina: De la belleza al tinku. En Tres reflexiones sobre el pensamiento andino, T. Bouysse-Cassagne, O. Harris, T. Platt \& V. Cereceda, Eds. pp. 133-231. La Paz: Biblioteca Andina 1, HISBOL.

Clastres, P., 1978. El arco y el cesto. En: La sociedad contra el Estado, A. Roa, Ed., pp. 207-230. Barcelona: Monte Ávila Editores

Descola, P., 2011. L'écologie des autres. L'anthropologie et la question de la nature. Sciences en Questions. Versailles: Éditions Quæ.

Descola, P., 2012. Más allá de la Naturaleza y la Cultura. Buenos Aires: Amorrotou ediciones.

Fernández Chiti, J., 1998. La simbólica en la cerámica indígena argentina. Buenos Aires: Ediciones Condorhuasi.

Gallardo, F.; P. Mege, J. L. Martínez \& L. Cornejo, 1990. Moche, señores de la muerte. Santiago: Museo Chileno de Arte Precolombino.

GASTALDI, M. R., 2010. Cultura material, construcción de identidades y transformaciones sociales en el valle de Ambato durante el primer milenio d. C. Tesis para optar al grado de Doctor, Universidad Nacional de La Plata.

Gonź́lez, A. R., 1964. La cultura de la Aguada del N. O. Argentino. Revista del Instituto de Antropología 2-3: 205-253.

González, A. R., 1977. Arte precolombino de la Argentina, introducción a su bistoria cultural. Buenos Aires: Filmediciones Valero.

GonzÁlez, A. R., 1998. Arte precolombino. Cultura La Aguada, arqueología y diseños. Buenos Aires: Filmediciones Valero.

GORDILLO, I., 2009. El sitio ceremonial de La Rinconada: Organización socioespacial y religión en Ambato, (Catamarca, Argentina). Oxford: British Archaeological Reports, International Series 7.

Goretti, M., 2006. Tesoros precolombinos el Noroeste argentino. Buenos Aires: Fundación Cepia.

Goretti, M., 2007. Antes de América. Símbolos de culto y poder en las culturas prehispánicas. Buenos Aires: Fundación Cepia.

HASTORF, C. \& S. JOHANNESSEN, 1991. Understanding changing people/ plant relationship in the prehispanic Andes. En Processual and Posprocessual Archaeology, Multiples ways of knowing the past, Occasional paper $n^{\circ} 10$, R. Preucel, Ed., pp. 140-155, Southern Illinois. University at Carbondale.

Howes, D., 2006. Scent, sound and synaesthesia. Intersensoriality and material culture theory. En Handbook of Material Culture, C. Tilley; W. Keane, S. Kuechler, M. Rowlands \& P. Spyer, Eds., pp. 161-172. London: SAGE Publications Ltd.

KNOBLOCH, P., 2000. Wari ritual power at Conchopata: An interpretation of Anadenanthera colubrina iconography. Latin American Antiquity 11 (4): 387-402.

Kopenawa, D. \& B. Albert, 2010. La Chute du Ciel. Paroles d'un chaman Yanomami. Paris: Collection Terre Humaine, Ed. Plon.

Kounen, J. ; J. Narby \& V. RAVAlEC, 2008. Plantes et Chamanisme. Conversations autour de l'Ayahuasca E del'Tboga. Paris: MAMA Editions.

Kush, M. F., 1991. Forma, diseño y figuración en la cerámica pintada y grabada de la Aguada. En El arte rupestre en la arqueología contemporánea, M.M. Podestá, M. I. Hernández Llosas \& S. F. Renard de Coquet, Eds., pp. 14-24. Buenos Aires: Sociedad Argentina de Antropología, Asociación Amigos del Instituto Nacional de Antropología y Pensamiento Latinoamericano.

Laguens, A., 2004. Arqueología de la diferenciación social en el valle de Ambato, Catamarca, Argentina (s. II-VI d.C.): El actualismo como metodología de análisis. Relaciones de la Sociedad Argentina de Antropologia 29: 137-162, Buenos Aires.
LAGUENS, A., 2006. Espacio social y recursos en la arqueología de la desigualdad social. En Contra la tiranía tipológica en arqueología. Una visión desde Suramérica, C. Gnecco \& C. Langebaek, Eds., pp. 99 - 119. Bogotá: Universidad de los Andes.

Laguens, A. \& M. Gastaldi, 2008. Registro material, fisicalidad, interioridad, continuidad y discontinuidad: posiciones y oposiciones frente a la naturaleza y las cosas. En Puentes hacia el pasado, reflexiones teóricas en arqueología, D. Jackson, D. Salazar \& A. Troncoso, Eds., pp. 169-189. Santiago: Editorial Área de Arqueología de la Universidad de Chile.

Latour, B., 1991. Nous n'avons jamais été modernes. Essai d'anthropologie symetrique. Paris: La Decouverte.

Llamazares, A. M. \& C. Martínez Sarasola, 2006. Reflejos de la cosmovisión originaria. Arte indígena y chamanismo en el Noroeste Argentino prehispánico. En Tesoros precolombinos el Noroeste Argentino, M. Goretti, Ed., pp. 63-91. Buenos Aires: Fundación Cepia.

Lema, V., 2014. Criar y ser criados por las plantas y sus espacios en los Andes Septentrionales de la Argentina. En Espacialidades altoandinas. Nuevos aportes desde la Argentina, Tomo I: Miradas hacia lo local, lo comunitario y lo doméstico, A. Benedetti \& J. Tomassi, Comps., pp. 301-338. Buenos Aires: Ed. F. Filosofía y Letras.

Lewis-Williams, D. \& D. Pearce, 2009. Dentro de la mente neolítica: Consciencia, cosmos y el mundo de los dioses. Madrid: Akal.

Marconetto, M. B., 2008. Recursos forestales y el proceso de diferenciación social en tiempos prehispánicos. Valle de Ambato, Catamarca. Oxford: BAR South American Archaeology Series n ${ }^{\circ} 3$.

Mulvany, E., 1984. Motivos fitomorfos de alucinógenos en Chavin. Chungara 12: 57-80.

NARBy, J. \& F. HuXley, 2009. Anthologie du Chamanisme. Cinq cents ans sur la piste du savoir. Paris: Collection Espaces Libres.

NASTRI, J., 2008. La figura de las largas cejas de la iconografía Santamariana. Chamanismo, sacrificio y cosmovisión calchaquí. Boletín del Museo Chileno de Arte Precolombino 13 (1): 9-34.

Отт, J., 1996. Pharmacoteon: Drogas enteógenas, sus fuentes vegetales y su historia. Barcelona: Los libros de la liebre.

Pazzarelli, F., 2011. Arqueología de la comida. Cultura material y prácticas de alimentación en Ambato, Catamarca (Argentina), siglos v-xi. Tesis para optar al grado de Doctor en Ciencias Antropológicas, Universidad Nacional de Córdoba.

Pazzarelli, F., 2014. O rastro do pastor. Criação de animais e técnicas para fazer carne em Jujuy (Andes Meridionais, Argentina). Anais do seminário de antropologia da UFCAR 1 (1): 430-443, São Carlos.

Pérez Gollán, J. A., 1986. Iconografía religiosa andina en el NOA. Boletín del Instituto Francés de Estudios Andinos xv (3-4): 23-33.

Pérez Gollán, J. A., 1991. La Cultura de La Aguada vista desde el Valle de Ambato. Publicaciones del Ciffyh 46: 47-99.

Pérez Gollán, J. A. \& I. Gordillo, 1993. Alucinógenos y sociedades indígenas del Noroeste Argentino. Anales de Antropología 30: 10-25. México, D.F.: Instituto de Investigación Antropológica, UNAM.

Sharon, D., 2004. El Chamán de los cuatro vientos. México: Siglo XXI Editores.

Strathern, M., 1980. No nature, no culture: The Hagen case. En Nature, Culture and Gender, C. Mac Cormack \& M. Strathern, Eds., pp. 174-222. Cambridge: Cambridge University Press.

Torres, C., 2013. Apuntes sobre el género Anadenanthera y su uso en los Andes precolombinos. Peripheria 15: 20-29, Huaraz.

Viveiros de CASTro, E., 2004. Perspectivismo y multinaturalismo en la América indígena. En Tierra adentro, territorio indigena y percepción del entorno, A. Surallés \& P. García Hierro, Eds., pp. 37-79. Lima: Grupo internacional de trabajos sobre asuntos indígenas.

Viveiros de Castro, E., 2010. Metafísicas caníbales. Líneas de Antropologia posestructural. Madrid: Katz Editores.

VIVEIROS DE CASTRO, E., 2012. Cosmological perspectivism in Amazonia and elsewhere. Masterclass Series 1. Manchester: HAU Network of Ethnographic Theory.

YACOVLEFF, E. \& F. L. HeRRERA, 1934. El mundo vegetal de los antiguos peruanos. Revista del Museo Nacional 3 (3): 243-322, Lima. 
